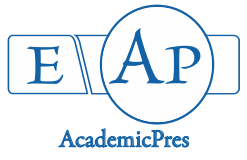

Sharma AD and Kaur I (2021)

Notulae Scientia Biologicae 13(1):10854

DOI: $10.15835 / \mathrm{nsb} 13110854$

Research Article

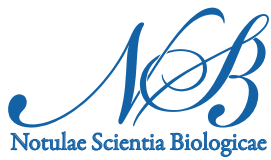

\title{
By-product hydrosol of Eucalyptus globulus essential oil distillation as source of botanical insecticides: wealth from waste
}

\author{
Arun D. SHARMA*, Inderjeet KAUR \\ Lyallpur Khalsa College, PG Department of Biotechnology, Jalandhar, Punjab, India; \\ arundevsharma47@gmail.com (*corresponding author); inderjeetbiotechlkc@gmail.com
}

\begin{abstract}
Worldwide use of chemical pesticides is on rise which is creating a big problem to environment and human health. Hence great interest has been generated to find out botanical leads having anti-pest properties from medicinal plants. The objective of this work was to evaluate the insecticidal potential of Eucalyptus globulus waste hydrosol obtained after essential oil distillation. Samples of Eucalyptus globulus genus were collected from near-by areas of study, and were hydro-distilled and their by-product 'hydrosol was analyzed for phenolics and tannin determination. UV-VIS, FT-IR and fluorescent study was also conducted of by-product hydrosol. In addition, insecticidal activity of by-product hydrosol was also monitored against mealy bug. Substantial amount of phenolics and tannins were detected in the by-product hydrosol. UV and fluorescent spectroscopy revealed the presence of secondary metabolites. Significantly higher insecticidal activity was observed of by-product hydrosol against mealy bug. The results suggested that by-product hydrosol from Eucalyptus globulus essential oil distillation can be considered as potential candidates for bio-control of pests.
\end{abstract}

Keywords: botanicals; insecticide; plant allelochemicals; plant protection; toxicity

\section{Introduction}

Worldwide insect pest management is facing ecological and economic challenge owing to the environmental hazards due to extensive use of synthetic pesticides chemicals. Highly strong pesticides like organophosphate compounds are routinely and extensively used chemicals. Due to extensive use of synthetic pesticides insects have developed resistance in parasite populations. Besides, their continues use was coupled with environmental pollution and health issues due to contamination of ground water by leaching and toxicity of the chemicals (Pamo et al., 2005). Thus, there is growing interest in identification of novel effective botanical natural compounds which are being considered as vital alternative strategy for the sustainable insect pest management in agriculture (Isman, 2000). Natural botanical compounds containing active insecticidal phytochemicals are appear to be biodegradable and potentially suitable for use in integrated pest-management controls and promising molecules to address some of these problems. It was also suggested that natural botanical extracts are complex in nature which contains numerous compounds as compared to synthetic pesticides, thus delays the buildup of insect resistance (Rattan, 2010).

Secondary metabolites which are present in plants apparently function as defense (toxic) molecules which inhibit reproduction and other biochemical process inside the insects thus lethal to them. The major

Received: 23 Nov 2020. Received in revised form: 25 Jan 2021. Accepted: 28 Jan 2021. Published online: 01 Feb 2021.

From Volume 13, Issue 1, 2021, Notulae Scientia Biologicae journal will use article numbers in place of the traditional method of continuous pagination through the volume. 
bio-active components (allelochemicals) of secondary metabolites which are produced by plants such as alkaloids, flavonoids, phenols, saponins, generally produced by plants as defense mechanism and reduce insect attack (Gao et al., 2012). Such botanical allelochemicals function as chemical defense compounds and influence molecular targets in herbivores and other microbes too. Plant essential oils are also secondary metabolites being derived from aromatic plants. These are complex, volatile, bioactive rich chemical molecules having alcohols and esters, and other aromatic compounds (Batish et al., 2008). It was studied that essential oils and their constituents affect biochemical process within insects and specifically disrupts insect endocrine system. However, studies pertaining to by-product wastes generated during hydrodistillation process of essential oil distillation are still not well known. Therefore, the objective of the present study was to evaluate the in vivo bioinsectisidal efficacy of by-product waste 'hydrosol obtained from Eucalyptus globulus after essential oil distillation for the control of mealy bug (Phenacoccus solenopsis Tinsley). Mealy bugs are insects which belong to family Pseudococcidae, are unarmored scale insects found in warm and moist habitats (Gary et al., 2003). These insects are considered as pests because they feed on plant juices of house, garden and green house plants and also act as a vector for several plant diseases. These insects are major reason behind loss of many ornamental, food and other agriculturally based crops (Sharma and Pati, 2013). Eucalyptus, member of Myrtaceae family, is a fast-growing tree which reaches height up to 25-50 meters. This tree can grow in wide climatic conditions, and thrives best in tropical to temperate conditions. This tree can tolerate drought stress hence can be cultivated in drought areas and waste lands with temperature range from $0-47^{\circ} \mathrm{C}$ (Goodger et al., 2016). The Eucalyptus consists of approximately 900 species and distributed all over the world due to its easy adaptability, ease of cultivation, tolerance to a wide range of environmental conditions and fast growth. Eucalyptus globules, native to Tasmanian and South-East Australia, member of Myrtaceae family is one of most widely spread genera. The leaves of this plant are used to extract Oleum eucalypti (eucalyptus oil) worldwide. Essential oil (EO) from this aromatic plant has long history to be used as traditional medicine in ancient times. Due to enriched presence of 1,8-cineole in its essential oil, leaf extracts from this plant is widely used as a raw material in pulp, cosmetic, pharmaceutical, food beverage, aromatherapy and phototherapy (Cimanga et al., 2002).

\section{Materials and Methods}

\section{Extraction of eucalyptus essential oil and by-product waste}

The leave samples of Eucalyptus globules were collected from trees growing under the natural conditions, from nearby areas of Lyallpur Khalsa College, Jalandhar, located at $71^{\circ}-31^{\circ}$ east latitude and $3^{\circ}$ $33^{\circ}$ north longitude. The city experiences humid subtropical climate with hot and cold months. The climate is dry on the whole. The experiment was conducted on July 2020. Steam-distillation method was used for extracting of essential oil. Extraction was performed using Clevenger-type apparatus. About $15 \mathrm{~g}$ of crushed green leaves were distilled at a working temperature of $100^{\circ} \mathrm{C}$ for $2 \mathrm{~h}$ with addition of $100 \mathrm{ml}$ of double-distilled water. Extraction of oil continued until no more oil was retrieved. The oil was collected from Clevenger apparatus and stored at laboratory condition $\left(25^{\circ} \mathrm{C}\right)$. Simultaneously, the by-product waste hydrosol (as shown in Figure 1) which was obtained during the process of distillation was also collected. The by-product obtained was used without further purification or filtration.

\section{UV-VIS spectral, FT-IR analysis, Fluorescence analysis of aqueous tea extract}

UV-spectrophotometric analysis by-product waste in the range of $200-400 \mathrm{~nm}$ was conducted using UV-VIS spectrophotometer (Labtronics) with slit width of $2 \mathrm{~nm}$, using a $10-\mathrm{mm}$ cell at room temperature. The peak values of the UV-VIS were recorded. FT-IR was used to identify functional groups. A small amount of by-product waste was taken in the sample cup of a diffuse reflectance accessory. IR spectrum was obtained using FT-IR infrared spectrophotometer (Perkin Elmer, USA spectrophotometer). The sample was scanned from 4000 to $400 \mathrm{~cm}^{-1 .}$ The peak values of the FT-IR were recorded. The fluorescence spectrum of by-product 
waste hydrosol was measured on Perkin Elmer Spectrophotometer (FL6500) with excitation wavelength of $380 \mathrm{~nm}$ using $2 \mathrm{ml}$ of tea sample. All experiments were done at room temperature $\left(\sim 30^{\circ} \mathrm{C}\right)$.

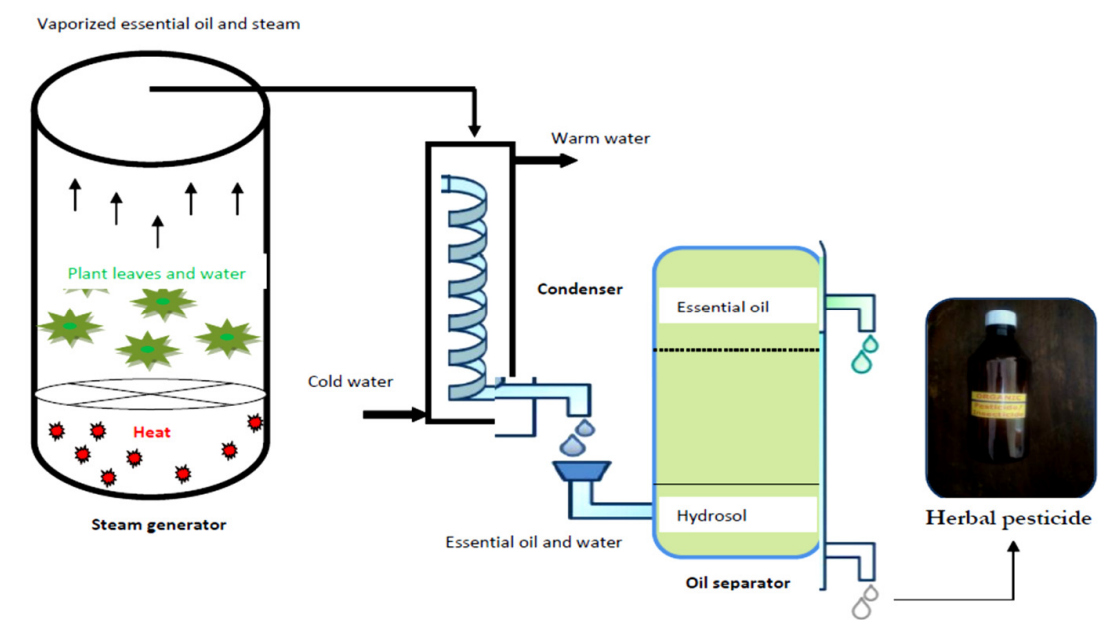

Figure 1. Pictorial representation of essential oil distillation and obtained by-product

\section{Total phenolic content}

The total phenolic content of the by-product waste hydrosol was measured by the Folin-Ciocalteu method. Briefly, different sample volumes (100-500ul) of by-product waste were made up to $3 \mathrm{~mL}$ with double distillate water and then mixed properly with $0.5 \mathrm{~mL}$ of 1:10 Folin-Ciocalteu reagent and incubated for 3 minutes. After incubation, $2 \mathrm{~mL}$ of $20 \%$ (w/v) sodium carbonate was added. The resulting solution was incubated for 60 minutes in the dark before absorbance readings were measured at $650 \mathrm{~nm}$. Gallic acid (5$50 \mu \mathrm{g} / \mathrm{mL}$ ) was used in the calibration curve. Result were expressed as mg gallic acid (GAE)/10kg fresh weight using the standard curve equation $y=0.212 x+0.294, R^{2}=0.821$. All the sample were analysed in triplicate.

\section{Total tannin content}

Tannin content was determined by Folin-Ciocalteu method. Different aliquots of by-product waste hydrosol were added to $7.5 \mathrm{ml}$ of distilled water and $0.5 \mathrm{ml}$ of Folin-Ciocalteu phenol reagent, $1 \mathrm{ml}$ of $35 \%$ sodium carbonate solution. Total reaction volume was made up to $10 \mathrm{ml}$ with distilled water. The mixture was vortexed well and kept at room temperature for $30 \mathrm{~min}$. Absorbance for test and standard solutions were measured against the blank at $700 \mathrm{~nm}$. The tannin content was expressed in terms of $\mathrm{mg}$ of tannic acid equivalents per $\mathrm{g}$ fresh weight of sample using the standard curve equation $\mathrm{y}=0.442 \mathrm{x}+0.09, \mathrm{R}^{2}=0.988$. The estimation of the tannin content was carried out in triplicate.

\section{Insecticidal activity}

Insecticidal activity of by-product waste hydrosol was performed on plants of Tagetus erecrta (commonly known as 'genda') naturally infested with mealy bug insect. For this, natural plant of 'genda' with pots having mealy bug infestations were collected from garden area of the college campus. Plants containing pots were kept under net house natural conditions. To determine the effect of by-product waste, 'genda' plants were sprayed with by-product waste for 0,3 and 7 days. Un-sprayed plants were taken as controls. After indicated sprays, plants were monitored and photographed. 


\section{Results and Discussion}

In agriculture, insect pest management system is facing multiple challenges due to routine and extensive use of synthetic chemicals. Even the most commonly used insecticides are becoming ineffective due to the development of insect resistance in addition to environment pollution and health risks of insecticides (Wall, 2007). These problems have inspired a great deal of research work to look for alterative eco-friendly natural products. Since botanical are biodegradable, less likely to cause ecological damage, a large number of plants have been taped to identify botanicals having insecticidal properties. In addition to advantages and safety aspects of botanicals over synthetics, it also gives farmers the key psychological satisfaction (Rattan, 2010). For this purpose, we evaluated insecticidal activity of by-product waste water after essential oil distillation for alternative management of mealy bug insects. Application of essential oil and plant extracts for the control of pest have been used for hundred years by community people and practitioners of traditional medicine (Koul et al., 2008; Rattan, 2010).

In plants secondary metabolites such as phenolics and tannins have been reported as candidates for insecticidal compounds that could be an effective alternative strategy in insect pest management. Our study confirmed that the by-product waste hydrosol was rich in phenolics and tannins. The estimated phenolic and tannin content in by-product waste hydrosol was $10 \mu \mathrm{g}$ per $\mathrm{ml}$ and $5 \mu \mathrm{g}$ per $\mathrm{ml}$, respectively, indicating that extract was rich in phytochemical active compounds. Further, The UV-VIS spectroscopy was performed to identify the bioactive compounds containing $\pi$-bonds, $\sigma$-bonds and lone pair of electrons, chromrophores and aromatic rings. The qualitative UV spectroscopy profile of by-product waste hydrosol revealed sharp peak at about $220 \mathrm{~nm}$ with absorbance of 2.6, indicating the accumulation of secondary metabolites. In UV-profile, occurrence of peaks in the region from 200-400 nm is clear indication of the presence of unsaturated groups and heteroatoms such as S, N, O (Parekh and Chanda, 2007). Occurrence of peaks at 200-400 nm reveals the presents of phenolic acid and alkaloids in the by-product waste water from Eucalyptus globulus essential oil distillation. On comparison of the spectra of leaves with literature value, shows that the extract has some similar phenolics and tannins as reported in by Paulraj et al. (2011), Niara et al. (2016).

In addition to UV-VIS, florescent spectroscopy is more reliable and sensitive method for detection of bio-molecules. Auto-fluorescent molecules are abundant in plant cells and their spectral images often used to analyse their spectra which give information about their accumulation and function under environmental conditions. Secondary metabolites and proteins are exclusively modulated in plants in response to interaction with environment (Mylle et al., 2013). However, yielding information about their fluorescent based phytochemical analysis in by-product waste is still not known. Spectral signatures of by-product waste hydrosol are illustrated in Figure 2B. Extracts showed the presence of fluorescent metabolites. Different metabolites when excited with radiation of suitable wavelength, molecules widely distributed in tissue like proteins, coenzymes, flavonoids, phenolics, alkaloids, chlorophylls, cell wall component etc behave as endogenous flurophores. By-product 'water' of Eucalyptus globulus essential oil distillation when excited at wavelength 300 $\mathrm{nm}$, a peculiar spectral fingerprint in green fluorescent region (GFR) region were detected. Both major and minor peaks with different fluorescence quantum yields were detected in all the plants which was attributed to the presence of secondary metabolites like phenolics or tannins. Fingerprints were detected in green florescent region (GFR) which may be attributed to the presence of phenolics, flavonoids, terpenoids and flavins like FAD, FMN. Cellular structures are believed to be protected from harmful effect of abiotic stresses by accumulating fluorescent secondary metabolites like terpenoids, carotenoids, phenolics which are important in pants for their normal growth and development (Lang et al., 1991). 

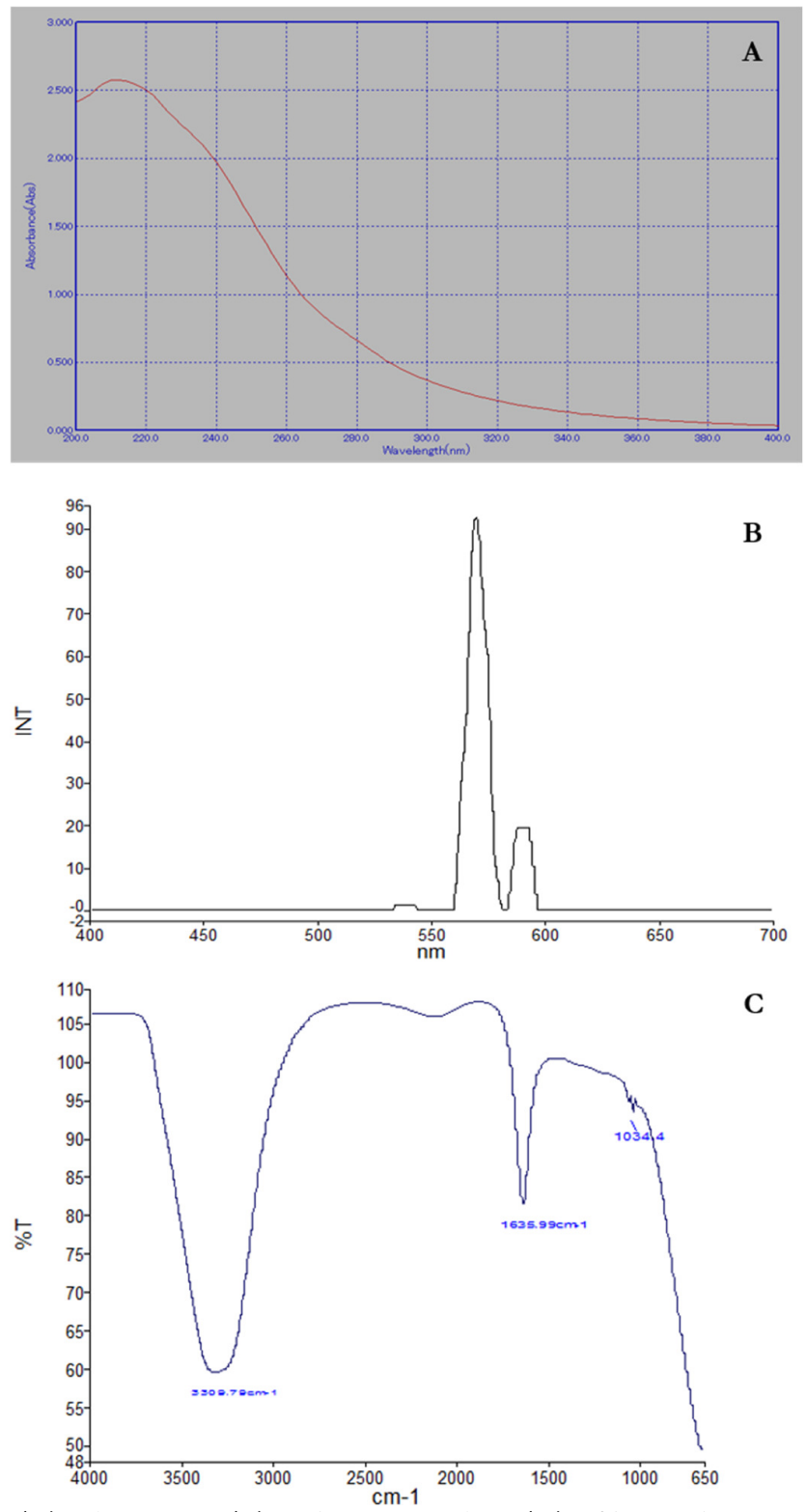

C

Figure 2. UV-VIS (A), Fluorescent (B) and FT-IR analysis (C) of by-product waste from Eucalyptus globulus essential oil distillation

Fourier Transform Infrared Spectrophotometer (FT-IR) is perhaps most powerful, rapid, non destructive method to fingerprint plant extracts or powders and for detecting types of bonds and functional groups present in the extracts (Karpagasundari and Kulothungan, 2016). By interpreting the IR absorption spectrum, the chemical bonds in a compound can be determined. The FT-IR profile is illustrated in Figure 2C. Hydrosol showed the presence of bio active compounds in all plants. In FTIR spectrum gave a broad peak at $3406 \mathrm{~cm}^{-1}$ which indicated the presence of $\mathrm{O}-\mathrm{H}$ stretching due to alcohols. It showed peaks at about 1600 $\mathrm{cm}^{-1}$ attributed to $\mathrm{C}-\mathrm{H}$ bending and C-C stretching due to alkanes ands alkenes. The peak around 1000 were due to aromatic and phenols. FT-IR spectrum confirmed the presence of aromatic compounds, alcohols, phenols, alkanes, alkynes, and amines in plant extracts (Liu et al., 2006). All these compounds belong to the secondary plant metabolites (Paulraj et al., 2011). 
Figure 3 indicates the anti-parasitic activity of by-product 'hydrosol of Eucalyptus globulus essential oil distillation against mealy bug parasite. Insecticidal activity was monitored after 0 DAS (day after spray) to 7 DAS. Notably, after 7 DAS no sign of mealy bug insect was detected, indicating lethal nature of by-product waste hydrosol. However, interestingly control plants which are not treated with by-product waste water showed the sign of total wilting and abnormal growth. The mortality of mealy bug insects may be due to the octopaminergic nervous system interference by the bio-active components of by-product waste hydrosol. Similarly, the insecticidal activity could be ascribed to complex nature of secondary metabolites like phenolics and tannins. Most of secondary metabolites like phenolics and alkaloids are reported as candidates for insecticidal compounds that could be alternative to synthetic pesticides. These secondary metabolites like phenolics, terpenes, sterols, waxes, fats, tannins, sugars, gums, resin and suberins defend plants against insects, pests and microbes. Our findings that by-product have insecticidal activity is in line with several studies where indicated that many plant extracts showed insecticidal and anti-parasitic properties could possibly against phytophagous pests, ticks and mites.

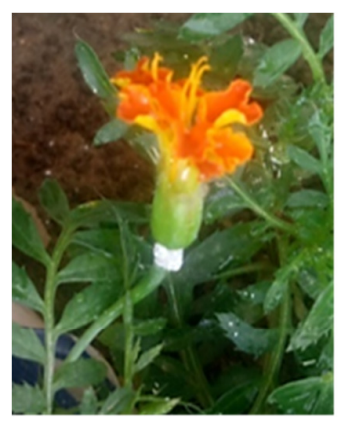

0

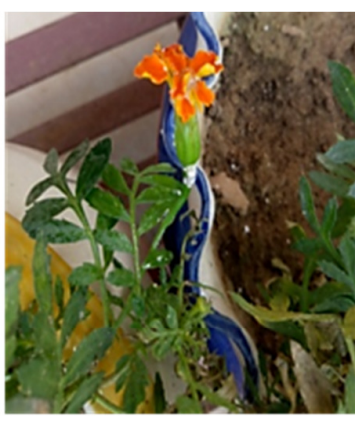

3

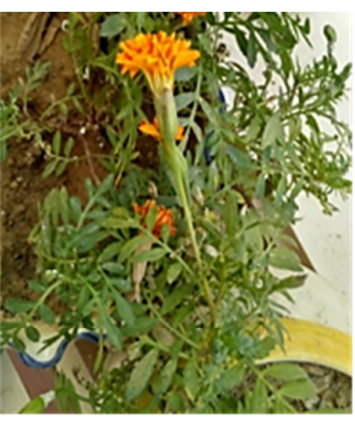

7

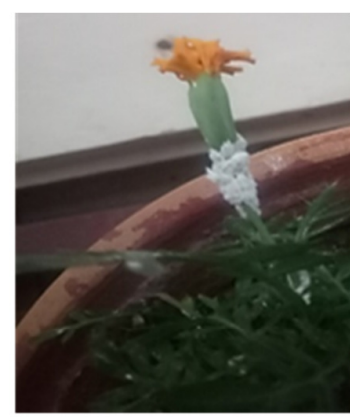

C

\section{DAS}

Figure 3. In vivo insecticidal activity of by-product waste from Eucalyptus globulus essential oil distillation DAS: days after spray, C: untreated plant (control).

\section{Conclusions}

To conclude, the current study showed that by-product waste hydrosol from essential oil distillation has strong insecticidal activity. The current study offers some scientific credence to the use of botanical compounds over synthetic pesticides in insect pest management. By-product waste hydrosol could be safe and eco friendly alternative to chemical pesticides. However, there is need for further investigation on their safety and efficacy both under in vivo and natural conditions as well as cost effectiveness of the herbal products that exhibited strong anti-pesticide activities with a view of replacing the conventional organophosphorus drugs. Further studies on isolation, purification, fractionation and characterization of responsible active phytocomponents of plant materials

\section{Authors' Contributions}

ADS: Designed and executed the study; IK: executed the study. All authors read and approved the final manuscript. 


\section{Acknowledgements}

This work was supported by DST-SEED, Government of India.

\section{Conflict of Interests}

The authors declare that there are no conflicts of interest related to this article.

\section{References}

Iori A, Grazioli D, Gentile E, Marano G, Salvatore G (2005). Acaricidal properties of the essential oil of Melaleuca alternifolia Cheel (tea tree oil) against nymphs of Ixodes ricinus. Veterinary Parasitology 129:173-176. https://doi.org/10.1016/j.vetpar.2004.11.035

Isman MB (2000). Plant essential oils for pest and disease management. Crop Protection 19:603-608. https://doi.org/10.1016/S0261-2194(00)00079-X

Jahn GC, Beardsley JW, González-Hernández H (2003). A review of the association of ants with mealybug wilt disease of pineapple. Proceedings of the Hawaiian Entomological Society 36:9-28. http://hdl.handle.net/10125/95

Karpagasundari C, Kulothungan S (2014). Analysis of bioactive compounds in Physalis minima leaves using GC MS, HPLC, UV-VIS and FTIR techniques. Journal of Pharmacognosy and Phytochemistry 3:196-201.

Koul O, Walia S, Dhaliwal GS (2008). Essential oils as green pesticides: potential and constraints. Biopesticides International 4:63-84.

Lang M, Stober F, Lichtenthaler HK (2005). Fluorescence emission spectra of plant leaves and plant constituents. Radiation and Environmental Biophysics 1191(30):333-347. https://doi.org/10.1007/BF01210517

Lee H (2004). Acaricidal activity of constituents identified in Foeniculum vulgare fruit oil against Dermatophagoides spp. (Acari: Pyroglyphidae). Journal of Agricultural and Food Chemistry 52:2887-2889. https://doiorg/10.1021/jf049631t

Liu H-X, Sun S-Q, LvG-H, Chan KKC (2006). Study on Angelica and its different extracts by Fourier transform infrared spectroscopy and two-dimensional correlation IR spectroscopy. Spectrochimica Acta Part A: Molecular and Biomolecular Spectroscopy 64:321-326. https://doi.org/10.1016/jsaa.2005.07.026

Mylle E, Codreanu MC, Boruc J, Russinova E (2013). Emission spectra profiling of fluorescent proteins in living plant cells. Plant Methods 9:1-8. https://doi.org/10.1186/1746-4811-9-10

Pamo ET, Tendonkeng F, Kana JR, Payne VK, Boukila B, Lemoufouet J, ... Nanda AS (2005). A study of the acaricidal properties of an essential oil extracted from the leaves of Ageratum houstonianum. Veterinary Parasitology 128(34):319-323. https://doi.org/10.1016/j.vetpar.2004.10.022

Parekh J, Chanda V (2007). In vitro antimicrobial activity and phytochemical analysis of some Indian medicinal plants. Turkish Journal of Biology 31:53-58.

Paul KR, Irudayaraj V, Johnson M, Patric DR (2011). Phytochemical and anti-bacterial activity of epidermal glands extracts of Christella parasitica (L.) H. Lev. Asian Pacific Journal of Tropical Biomedicine 1(1):8-11. https://doi.org/10.1016/S2221-1691(11)60059-2

Porto NM, Barros YLD, Basílio IJ, Agra MDF (2016). Microscopic and UV/Vis spectrophotometric characterization of Cissampelos pareira of Brazil and Africa. Revista Brasileira de Farmacognosia 26(2):135-146.

Rattan RS (2010). Mechanism of action of insecticidal secondary metabolites of plant origin. Crop Protection 29:913920. https://doi.org/10.1016/j.cropro.2010.05.008

Sharma A, Pati PK (2013). First record of Ashwagandha as a new host to the invasive mealybug (Phenacoccus solenopsis Tinsley) in India. Entomological News 123:59-62. https://doi.org/10.3157/021.123.0114

Wall R (2007). Ectoparasites: future challenges in a changing world. Veterinary Parasitology 148:62-74. https://doi.org/10.1016/j.vetpar:2007.05.011 
OPEN ACCESS The journal offers free, immediate, and unrestricted access to peer-reviewed research and scholarly work. Users are allowed to read, download, copy, distribute, print, search, or link to the full texts of the articles, or use them for any other lawful purpose, without asking prior permission from the publisher or the author.

(C) (9)

License - Articles published in Notulae Scientia Biologicae are Open-Access, distributed under the terms and conditions of the Creative Commons Attribution (CC BY 4.0) License.

(c) Articles by the authors; SHST, Cluj-Napoca, Romania. The journal allows the author(s) to hold the copyright/to retain publishing rights without restriction. 